Case Report

\title{
Mucinous carcinoma in young female mimicking as a phyllodes tumour- imaging and pathological correlation: a case report
}

\author{
Rajani Gorantla $^{1 *}$, Bhawna Dev ${ }^{1}$, Leena Dennis Joseph ${ }^{2}$, Priya Masilamani' ${ }^{1}$ Rupesh Mandava1
}

\begin{abstract}
${ }^{1}$ Department of Radiology, Sri Ramachandra University, Chennai, Tamil Nadu, India
${ }^{2}$ Department of Pathology, Sri Ramachandra University, Chennai, Tamil Nadu, India
\end{abstract}

Received: 29 April 2015

Accepted: 11 July 2015

*Correspondence:

Dr. Rajani Gorantla,

E-mail:drraaji@gmail.com

Copyright: ( ) the author(s), publisher and licensee Medip Academy. This is an open-access article distributed under the terms of the Creative Commons Attribution Non-Commercial License, which permits unrestricted non-commercial use, distribution, and reproduction in any medium, provided the original work is properly cited.

\section{ABSTRACT}

Mucinous carcinoma is a rare subtype of breast cancer characterised by abundant secretion of extracellular or intracellular mucin. In this article we highlight typical imaging findings of mucinous carcinoma and its histological subtypes mimicking phyllodes tumour.

Keywords: Breast cancer, Mucinous carcinoma, Phyllodes tumour

\section{INTRODUCTION}

Mucinous carcinoma is a subtype of invasive ductal carcinoma, also known as colloid carcinoma. It can occurs in all age groups, representing 2 to $7 \%$ of all cancers in old age and less than $1 \%$ in young women. ${ }^{1-3}$ WHO classification divides this tumour into three different subtypes: (i) mucinous carcinoma (ii) cystadenocarcinoma and columnar cell mucinous carcinoma and (iii) signet ring cell carcinoma. ${ }^{4}$

\section{CASE REPORT}

30 year old lady had noticed a lump in the left breast recently and came for further evaluation. No complains of pain, discharge or any other swelling in the same and contralateral breast. On clinical breast examination a smooth, well defined firm swelling was noticed in the left breast. USG of left breast done later showed an ovoid, well circumscribed heterogeneous mass with posterior acoustic enhancement. Few anechoic areas were seen within. No significant axillary lymphadenopathy was demonstrated either clinically or radiologically. The diagnosis of phyllodes was suspected. On excision biopsy, cut surface appeared slimy and shiny which strongly suggested that it could be a mucinous carcinoma. However this was confirmed on histopathology. Light microscopy showed atypical tumour cells with moderate to marked pleomorphism to be floating in lakes of extracellular mucin. Immunohisochemistry showed estrogen and progesterone receptor positivity (ER \&PR) and human epidermal receptor (HER 2) negative.

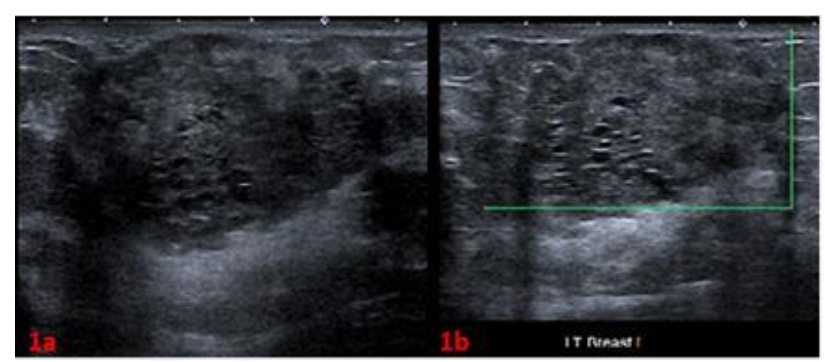

Figure 1: USG left breast shows heterogenous hypoechoic mass with posterior enhancement (1a). No colour flow on Doppler (1b). 


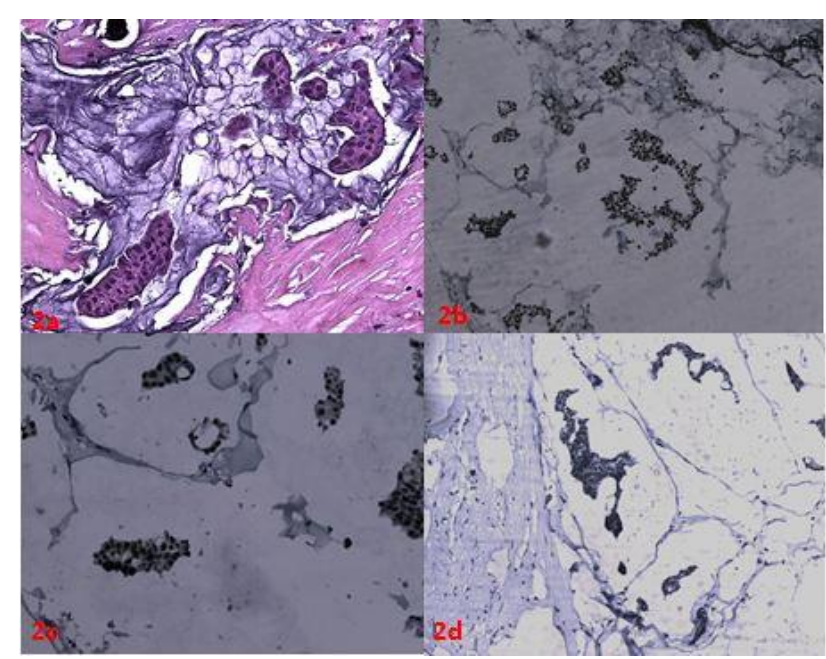

Figure 2: Light microscopy (H\&E stain x200) demonstrates atypical cells with pleomorphism in abundant mucin (2a). On immunohistochemistry cells are estrogen and progestrone receptor positive $(2 b \&$ 2c) and Her 2 negative (2d).

\section{DISCUSSION}

Mucinous tumours have variable amounts of mucin, which alters/influence the imaging appearance and prognosis prediction. Histologically they can be pure and mixed. Pure mucinous carcinomas are characterised by more than $90 \%$ of mucin cells occupying the entire mass. Mixed type contains component of invasive ductal carcinoma with extracellular mucin also known as invasive ductal carcinoma with mucinous degeneration. ${ }^{5}$ It is important to differentiate the two subtypes, as pure variety has better prognosis. ${ }^{6}$

\section{Imaging findings}

Mucinous carcinomas are part of well circumscribed malignant tumours appear as round, oval radio dense masses on X-ray mammography and diagnosed as benign lesions initially. ${ }^{7}$ Microlobulations can occur depending upon the amount of mucin. Pure mucinous tumours typically appear as well circumscribed round or ovoid dense masses. Mixed type shows spiculated or indistinct margins with heterogenous hypoechoic appearance due to desmoplastic reaction, as seen in other types of breast cancer. Microcalcifications may be also seen., Ultrasound has better sensitivity for detection of mucinous carcinoma. They appear as well circumscribed, round or ovoid mixed echogenic masses with solid and cystic components. Often appear as iso to hypoechoic to fat with posterior acoustic enhancement. ${ }^{8}$ Few of the benign tumours like phyllodes tumour and fibroadenoma have similar appearance on USG. So it is an imaging challenge to diagnose mucinous carcinoma.

MRI has higher sensitivity than mammography and USG for detection of mucinous carcinomas. Morphologically they have variable signal on $\mathrm{T} 1$ and hyperintense on $\mathrm{T} 2$ which is directly related to the amount of extracellular mucin. Mixed type appears heterogeneous on T2 weighted images. Kinetic evaluation of pure variety typically shows slow uptake in the early phase with persistent centripetal filling or plateu (type 1 or 2 kinetic curve) on delayed phase depending upon the cellularity and amount of mucin. Mixed type may show type 3 wash out kinetic curve. ${ }^{6,7}$

Histopathology: Core biopsy has high sensitivity than FNAC to diagnose mucinous carcinomas. However excision biopsy is required to differentiate pure and mixed types as prognosis and survival rate are different for pure and mixed types. Mucinous carcinomas are characterised by presence of cluster of cells within the extracellular mucin. The prognosis rate is better for pure mucinous carcinoma as they have slow indolent growth and metastasis of less than 15\%. ${ }^{9}$ They are mostly estrogen (ER) and progesterone (PR) receptor positive and human epidermoid growth factor HER 2 negative, which have favourable outcome. Recent studies have showed few cases of ER/PR negative and her 2 positivity and metastasis at presentation.

\section{CONCLUSION}

Mucinous carcinoma is a rare tumour in young females with imaging features mimicking the benign mass. It is important to consider it as one of the differential diagnosis if any heterogenous lobulated mass with posterior enhancement on USG is noted.

\section{Funding: No funding sources \\ Conflict of interest: None declared \\ Ethical approval: Not required}

\section{REFERENCES}

1. Rosen PP, Oberman HA, eds. Atlas of tumour pathology: tumours of the mammary gland, fasc 7, ser 3. Washington, DC: Armed Forces Institute of Pathology; 1993: 187-193.

2. Toikkanen, Kujari H. Pure and mixed mucinouscarcinomas of the breast: a clinicopathologic analysis of 61 cases with longterm follow-up. Hum Pathol. 1989;20:758-64.

3. Cardenosa G, Doudna C, Eklund G. Mucinous (colloid) breast cancer: clinical and mammo-graphic findings in 10 patients. Am J Radiol. 1994;162:1077-9.

4. Tavassoli FA, Devilee P. Tumors of the breast and female genital organs. In: Tavassoli FA, Devilee P, eds. World Health Organization Classification of Tumors. 2nd ed. Lyon, France: IARC Press; 2003.

5. Gustavo Nunes Medina Coeli, Henrique Ferreira dos Reis, Dayse Ribeiro Bertinetti, Francesca Maia Faria, Daniel Guimarães Tiezzi, Tatiane Mendes Gonçalves de Oliveira. Mucinous carcinoma of the breast: iconographic essay with histopathological correlation. Radiol Bras. 2013 Jul/Aug;46(4):242-6. 
6. Soo Youn Bae, Min-Young Choi, Dong Hui Cho, Jeong Eon Lee, Seok Jin Nam, Jung-Hyun Yang. Mucinous carcinoma of the breast in comparison with invasive ductal carcinoma: clinicopathologic characteristics and prognosis. J Breast Cancer. 2011 Dec;14(4):308-13.

7. Yoo JL, Woo OH, Kim YK, Cho KR, Yong HS, Seo BK, et al. Can MR imaging contribute in characterizing well-circumscribed breast carcinomas? Radiographics. 2010;30:1689-702.

8. Lam WW, Chu WC, Tse GM, Ma TK. Sonographic appearance of mucinous carcinoma of the breast. AJR Am J Roentgenol. 2004;182(4):1069-74.
9. Diab SG, Clark GM, Osborne CK, Libby A, Allred DC, Elledge RM. Tumor characteristics and clinical outcome of tubular and mucinous breastcarcinomas. J Clin Oncol. 1999;17(5):1442-8.

10. Kelli Y. Ha, Patricia DeLeon, William DeLeon. Invasive mucinous carcinoma of the breast. Proc (Bayl Univ Med Cent). 2013;26(3):295-7.

Cite this article as: Gorantla R, Dev B, Joseph LD, Masilamani P, Mandava R. Mucinous carcinoma in young female mimicking as a phyllodes tumourimaging and pathological correlation: a case report. Int Surg J 2015;2:418-20. 